Article

\title{
Characterizing Cyberbullying among College Students: Hacking, Dirty Laundry, and Mocking
}

\author{
Rajitha Kota ${ }^{1, *}$, Shari Schoohs ${ }^{1}$, Meghan Benson ${ }^{2}$, and Megan A. Moreno ${ }^{3,4}$ \\ 1 Department of Pediatrics, University of Wisconsin-Madison, Madison, WI 53792, USA; \\ E-Mail: schoohs@uwalumni.com \\ 2 Planned Parenthood of Wisconsin, Madison, WI 53713, USA; E-Mail: meghan.benson@ppwi.org \\ 3 Center for Child Health, Behavior and Development, Seattle Children's Research Institute, Seattle, \\ WA 98121, USA; E-Mail: megan.moreno@seattlechildrens.org \\ 4 Division of Adolescent Medicine, University of Washington, Seattle, WA 98121, USA
}

* Author to whom correspondence should be addressed; E-Mail: rkota@wisc.edu; Tel.: +1-262-271-7204.

External Editors: Conor Mc Guckin and Lucie Corcoran

Received: 15 August 2014; in revised form: 5 October 2014 / Accepted: 20 October 2014 / Published: 22 October 2014

\begin{abstract}
Bullying behaviors occur across the lifespan and have increasingly migrated to online platforms where they are known as cyberbullying. The purpose of this study was to explore the phenomenon of cyberbullying among college students. Participants were recruited for focus groups through purposeful sampling, including recruitment from groups traditionally at risk for bullying. Focus groups discussed views and perceptions of cyberbullying on campuses. Groups were led by a trained facilitator and were audio recorded and manually transcribed. The constant comparative approach was used to identify themes and representative quotations. The 42 participants had an average age of 19.2 (SD = 1.2), 55\% were female, $83 \%$ were Caucasian. Three themes emerged from the data: (1) lack of agreement on a definition of cyberbullying, but consensus on three representative scenarios: hacking, dirty laundry and mocking; (2) concerns with translating definitions of traditional bullying to cyberbullying; (3) opinions that cyberbullying may manifest differently in college compared to younger adolescents, including increased potential for long-term effects. College students were not in agreement about a theoretical definition, but they could agree upon specific representative instances of cyberbullying. Future studies could consider using common case examples or vignettes of cyberbullying,
\end{abstract}


or creation of developmentally representative definitions by age group.

Keywords: college student; bullying; cyberbullying; internet; focus group; Facebook; social media; online safety; young adult; LGBTQ

\section{Introduction}

Bullying occurs throughout the world and can happen at many stages in the life course-from childhood, to adolescence, even to adulthood. Though traditional "schoolyard" bullying still exists, in recent years the Internet has provided a new platform for bullying. There are many online platforms in which bullying may take place, including e-mail, blogs, social networking websites (e.g., Facebook, Twitter), online games and text messaging. This phenomenon has been called cyberbullying, electronic aggression or online harassment [1]. Several definitions of cyberbullying exist; most are predicated on accepted definitions for traditional bullying. One commonly used definition defines cyberbullying as "an aggressive, intentional act or behavior that is carried out by a group or an individual, using electronic forms of contact, repeatedly and over time against a victim who cannot easily defend him or herself [2]”.

Previous studies have examined the substantial psychological effects that cyberbullying can have on its victims [3]. Adolescents who have been cyberbullied report higher levels of depression and lower self-esteem [4]. Victims are also more likely to exhibit externalized hostility and delinquency [5]. Finally, cyberbullying victims report lower grades and other academic problems as a result of the experience [6].

Assessing the prevalence of cyberbullying remains a challenge because the field lacks an accepted operational definition of the term. One study of younger Canadian adolescents defined cyberbullying as "harassing using technology such as email, computer, cell phone, video cameras, etc.” In this study the prevalence rate of cyberbullying victimization was 25\% [7]. A second study of adolescents defined cyberbullying broadly as "mean things" or "anything that someone does that upsets or offends someone else" and found that $72 \%$ considered themselves victims of cyberbullying [8]. A third study defined cyberbullying more narrowly as "bullying through text messaging, email, mobile phone calls or picture/video clip.” This study found the prevalence of reported victimization to be $17.6 \%$ [3]. Using varied definitions of cyberbullying may lead individuals to report it differently based on how broadly or narrowly the term is defined. This range of reported prevalence across studies creates challenges in determining the magnitude of this problem and in developing appropriate prevention and intervention tools. The importance of achieving consensus on an approach to bullying was recently highlighted by the Centers for Disease Control's recent report on bullying [9].

Although much attention has been paid to bullying behaviors of younger teens, less is known about young adult college students. College students may be a population at risk for cyberbullying as they are among the highest users of the Internet and other forms of communication technology [10], and have greatly reduced parental oversight compared to younger adolescents. Current data suggest that up to $20 \%$ of college students have experienced cyberbullying, though the specific nature and perspectives of college students regarding this behavior remains unclear [11,12]. At present, efforts are ongoing by 
numerous scholars and groups toward understanding how to define cyberbullying, and whether cyberbullying falls completely within the purview of traditional bullying that affects younger adolescent populations. Our goals for this study were to understand key issues from the perspectives of college students that merit consideration in efforts to achieve a definition and age-appropriate understanding of this emerging phenomenon. Obtaining this information would provide a deeper understanding of how cyberbullying may change over the stages of adolescence; utilizing participant voices may provide a more resonant characterization of cyberbullying in this age group.

\section{Methods}

\subsection{Setting and Participants}

Focus group participants were recruited through purposeful sampling at a large Midwestern university between September 2011 and October 2012. Eligible subjects were current undergraduate students between the ages of 18 and 22 years. The University of Wisconsin-Madison and Seattle Children's Hospital Institutional Review Boards approved this study.

To enhance the depth and breadth of representation of campus groups, participants were purposefully recruited from a wide range of campus activities and groups. Recruitment methods included canvassing the annual student organization fair and attending student group meetings to generate interest in the study. Effort was made to sample students in groups that are traditionally more likely to be bullied such as lesbian, gay, bisexual, transgender and questioning (LGTBQ) students and racial/ethnic minorities $[8,13]$. We contacted interested participants to schedule them for a focus group ahead of time based on their availability, including offering focus group opportunities in evenings when students were unlikely to be in class. Students were offered opportunities to attend a group at the time of their choice to maximize convenience for study participants.

\subsection{Focus Groups}

A trained facilitator conducted semi-structured focus groups. Focus groups allow for interaction between participants as well as opportunities for participants to build on each other's thoughts $[14,15]$. Participants were asked open-ended as well as probing questions and encouraged to share their thoughts on how they viewed and defined cyberbullying in the college setting. Near the end of the focus group, participants were provided a common definition of cyberbullying based in traditional bullying. Participants were asked for their views on this definition in the context of the previous discussions. The definition of cyberbullying provided during groups was "an aggressive, intentional act or behavior that is carried out by a group or an individual, using electronic forms of contact, repeatedly and over time against a victim who cannot easily defend him or herself [2]”.

\subsection{Study Procedure}

Before the start of each focus group, participants completed an anonymous demographic survey, which included questions about age, year in school, and race/ethnicity. Students also indicated what kind of campus organizations they were involved with and their major in school, in order to assess that 
we were including views from students with a wide range of backgrounds. The facilitator then explained the purpose of the focus group. Each focus group lasted between 45 and 90 minutes.

\subsection{Analysis}

All audio recordings were transcribed verbatim with the exception of any identifying data such as names. Audio recordings were completed within seven-10 days of completion of the focus group. Data saturation was monitored during the focus group data collection by review of transcripts at scheduled intervals. It became clear that data saturation had been reached due to the commonality of ideas that emerged across groups.

Analysis was conducted using an open coding approach and the constant comparative method [16]. The constant comparative method is a qualitative methodology that requires the researcher to collect data prior to forming hypotheses. Once the data are collected, key points are coded and then arranged into groups or themes with similar conceptual meanings through several rounds of coding and meeting.

Analyses were conducted by three investigators (RK, SS, MM). All transcripts were initially read separately by the three investigators using an open coding approach. The three investigators then met to discuss coding schemes and outline common themes. After a second review of the transcripts, investigators discussed common themes and concepts using the constant comparative method [16]. At the final analysis meeting, the investigators discussed and reached consensus among major themes in the data and also determined illustrative quotations. Both themes and illustrative quotations required consensus by all three investigators in order to be included in the final results.

\section{Results}

\subsection{Participants}

A total of 42 students participated in six focus groups that ranged in size from three to 12 participants. Participants' average age was 19.2 (SD = 1.2), 55\% were female and 83\% were Caucasian. All participants contributed to the discussion and completed the demographic survey. Participants represented a wide range of majors and campus activities (Table 1).

Table 1. Demographic information and campus involvement for college student focus group participants $(\mathrm{n}=42)$

\begin{tabular}{|l|r|}
\hline \multicolumn{1}{|c|}{ Demographic Characteristics $(\mathrm{n}=42)$} & \% of participants \\
Gender & 54.8 \\
Female & 45.2 \\
Male & \\
Ethnicity & 83 \\
Caucasian & 11.9 \\
Asian/Pacific Islander & 4.8 \\
Hispanic/Latino & \\
\hline
\end{tabular}


Table 1. Cont.

\begin{tabular}{|c|c|}
\hline Demographic Characteristics $(n=42)$ & \% of participants \\
\hline \multicolumn{2}{|l|}{ Year in School } \\
\hline Freshmen & 42.8 \\
\hline Sophomores & 23.8 \\
\hline Juniors & 23.8 \\
\hline Seniors & 9.5 \\
\hline \multicolumn{2}{|l|}{ Major } \\
\hline Basic Sciences (e.g. Biology, Pre-Med, Math) & 16.6 \\
\hline Social Sciences (e.g. Psychology, Sociology) & 26.2 \\
\hline Humanities (e.g. History, English, Art) & 9.5 \\
\hline Engineering & 11.9 \\
\hline Business & 23.8 \\
\hline Journalism & 4.8 \\
\hline Undecided & 7.1 \\
\hline \multicolumn{2}{|l|}{ Student Organizations } \\
\hline Academic Groups & 14.3 \\
\hline Pre-Health Groups & 9.5 \\
\hline Student Life & 19.0 \\
\hline LGBTQ Groups & 9.6 \\
\hline Cultural and Ethnic Groups & 4.8 \\
\hline Greek Community & 26.1 \\
\hline Sports and Athletics & 4.8 \\
\hline None & 9.5 \\
\hline
\end{tabular}

\subsection{Themes}

Three major themes emerged from our data. First, there was a lack of agreement on a specific definition of cyberbullying but agreement upon three specific cases as representative. Second, participants noted key differences between traditional bullying and cyberbullying. Third, developmental differences in young adult cyberbullying, compared to adolescent cyberbullying, were highlighted by participants.

\subsubsection{Theme 1: No Agreement on Definition, but Consensus on Representative Cases}

Participants tried to achieve a definition of cyberbullying, but struggled to agree upon one. There were diverse opinions both within and across groups. Despite the fact that participants could not agree upon a definition statement, an interesting pattern emerged in each focus group in which specific examples of behaviors that were considered cyberbullying were discussed. These discussions often led to specific examples that were agreed upon as representative of cyberbullying among college students. These 3 scenarios that were commonly discussed and achieved consensus included:

(1). Hacking social media profiles: A commonly described behavior that was considered cyberbullying was "hacking” into a social media profile, such as Facebook, and posting inappropriate information. Hacking was described as Facebook user gaining access to another user's profile and 
posting information on that profile without permission. This phenomenon was often described as a scenario between roommates or former romantic partners. One example was described below:

“The worst thing I can think of is actually a girlfriend and a boyfriend. They broke up and the girlfriend knew the password to his Facebook and his e-mail and she changed his password and got the confirmation e-mail on his e-mail account and she had control of his account for like two weeks or something, and she was like, harassing other girls, [making comments] like, 'you were sleeping with him, you were dating him, weren’t you'. She ... like, legitimately took control of his Facebook and was using it for her own means and to embarrass him; she was posting like statuses and secrets.”

Another type of hacking described by participants was related to representing another student's sexual identity. Participants emphasized that this representation was not necessarily always targeted at a victim's actual sexual orientation. An example is described below:

"I remember I knew a guy...someone hacked his account and like changed everything to like rainbows and calling him gay and he was really upset about it. Like, the entire page and all of his pictures were like that. I would definitely consider that cyberbullying."

Participants who identified as LGTBQ pointed out that they had seen this phenomenon on Facebook but did not know of any specific hacking incidents within their personal community of LGTBQ students. However, some participants remarked that incidents of hacking into a Facebook profile to change a student's sexual orientation representation to gay or bisexual still had potential to reflect negatively on the LGTBQ community.

(2). Posting information about social discord publicly: Another commonly discussed type of cyberbullying was situations that involved social discord between roommates, romantic partners, or a campus group, and one member posting about it on a social media profile. This public documentation of an otherwise personal issue, or "airing dirty laundry" was considered cyberbullying. One example included:

“The only bad one I've heard of is a good friend of mine who in her first year here, her roommate and her weren’t getting along. So she didn’t even find out about it until her roommate posted on Facebook that 'I have the worst roommate ever.' And at first, it was taken as a joke but then she realized that there were some really bad tensions and I guess that was like a really indirect way of finding out that there was a big problem...so now a lot of people won't room with her next year because they're hesitant if she's a good person.”

(3). Public shaming from posted content: A final agreed upon cyberbullying technique was to publicly mock, tease or put down others related to their own posted content. Examples of this phenomenon included mocking a photograph another student had chosen to post, or purposefully posting a photograph that would embarrass another student. One participant described:

"Umm, one example I can think of is when someone posts that just awful like drunk picture of someone, you know what I mean, where they just look terrible, and then all these people comment and like it and say 'ha ha ha' and it just puts that person down. And like why even post it, do you know what I mean, there has to be some intention [to bully]...” 


\subsubsection{Theme 2: Differences between Traditional Bullying and Cyberbullying}

In discussing how to define cyberbullying, participants often began by reflecting on definitions and terms used in describing traditional bullying from the definition read to them during the group. Participants expressed concerns with several of these traditional bullying terms applied to cyberbullying.

\subsubsection{Aggression}

Participants suggested that including the word "aggressive" in a definition of bullying was appropriate for traditional bullying but not for cyberbullying, as they felt these terms were strongly associated with physical violence. Participants argued that cyberbullying did not need to involve aggression to be hurtful; an example comment is below:

"[Cyberbullying] could be a much more passive bullying than what it would be in real life.

In real life it would be a lot more active and aggressive, and through cyberbullying it could be really passive and still hurt.”

\subsubsection{Intention}

The concept of “intention” to describe a bully's approach to a victim was frequently discussed among participants. Intention is a hallmark of traditional bullying but its relevance to cyberbullying was debated. Many participants felt that cyberbullying can occur without intention. An example scenario was friends who take a joke too far online and post comments that are misinterpreted by a particular student. One participant noted:

"Who is doing the bullying? Is it a friend, because then apparently it's not bullying, it's not ill-intention, but if it's someone that you don't like [it is bullying]....”

Participants also felt that cyberbullies may not be aware of the potential seriousness of their behavior or its impact on the person. For example, though a cyberbully's intention may have been to mildly embarrass the victim, the bully may not realize they have greatly hurt or harmed the victim.

\subsubsection{Repetition}

Participants discussed that the concept of repetition of behavior, often associated with traditional bullying, may not apply to cyberbullying. Participants described that even one negative comment, picture, or video sent via texting or posted online could easily be circulated to many people via the Internet, so repetition could be viral rather than purposeful.

\subsubsection{Theme 3: Differences in Cyberbullying across Developmental Stages of Adolescence}

Participants engaged in lively discussions about their views on differences in cyberbullying across the stages of adolescence. Most participants agreed that in younger adolescence, such as during middle or high school, cyberbullying usually involved insulting someone's appearance or other superficial characteristics. In contrast, many students stated that college cyberbullying often involves offensively challenging others' ideas. Many students described how debates about politics, sexuality, and other 
social issues often take place online and then "devolve into heated arguments" that become personal attacks instead of civil disagreements. An example quotation from a research participant included:

"I think that [cyberbullying] is not as prevalent for college students, but still...especially politically, things can get heated and malicious pretty quickly and once it starts to get like personal attacks that definitely I think counts as cyberbullying and it happens.”

Participants also expressed their views that bullying in college could have a more profound impact on students' reputations or career prospects because of the personal nature of the attacks. One participant explained:

"I'd say, in high school, [cyberbullying] is much less serious, but it happens more often. Something that happens in high school probably won't ruin your life, but as a scandal in real life, if someone's spreading rumors about you when you're an adult, that's a much bigger deal. You could ruin someone’s entire livelihood. And their career.”

A common idea repeated in nearly every focus group was that adolescents reach a new level of maturity in college compared to high school. Participants who discussed the maturity of college students were also likely to downplay the possibility that cyberbullying was a problem in college; and behaviors that would be considered as cyberbullying in a middle or high school setting were only seen as humorous in college. Though a few participants emphasized their newfound maturity in college, these same participants commonly admitted to having engaged in the bullying behaviors that they had defined as immature. The following quotes were stated by the same participant and suggest a disconnect between perceived maturity and actual behaviors.

"I'd like to think college is more of a bully-free environment than high school or middle school...in general, people don’t care as much about who you are, what you like...”

“[Hacking people’s Facebook profiles], that happens all the time. It's like, probably like every other day that your newsfeed is filled with like, 'I'm gay, I'm gay'...it's just kind of funny..."

In one group there was a discussion about behaviors that were immature and unlikely to be done by college students. After this discussion one participant admitted to engaging in the behaviors that the focus group had previously identified as immature:

"Full disclosure here, my friend left his page up one time and I like sent a request to a girl he was kind of seeing, like a relationship request, and he didn't like that girl at all, he was just kind of hooking up with her and that like ended the relationship. Just cut off from her. I thought it was hilarious, but that's pretty bad.”

\section{Conclusions}

We conducted focus groups with college students towards characterizing the nature of cyberbullying in that population and defining key issues that may impact future efforts to define, understand and prevent cyberbullying. Consensus on a definition of cyberbullying remained elusive. This finding illustrates how challenging it can be to achieve consensus on an applicable definition of a 
societal concept, mirroring struggles that professional groups may have encountered in developing a clear definition of cyberbullying. These mixed views of what constitutes cyberbullying may explain why previous studies present a variety of prevalence rates [6,7,11,17].

While a consensus on a definition of cyberbullying remained elusive, there was consensus reached across groups on representative cases of cyberbullying including hacking, airing dirty laundry and mocking. The inclusion of airing dirty laundry as a representative case raises key questions regarding how society should approach defining cyberbullying and whose input should be prioritized. College administrators and scholars in related fields may question whether "airing dirty laundry" meets criteria as bullying, or whether it represents behavior that, while unpleasant, should not be considered cyberbullying. It remains unclear whether a definition of cyberbullying should prioritize views of age-appropriate groups involved who experience cyberbullying themselves, or whether a definition should prioritize views and experiences from adult scholars or experts in bullying. While our study cannot answer this question, our findings raise key issues that merit consideration in how to create a definition of cyberbullying that has relevance across different age groups and professional societies.

Many of our participants engaged in discussions about differences between traditional and online bullying. Participants were quick to identify ways in which cyberbullying differed from traditional bullying, including a reduced emphasis on aggression, intention and repetition. It is possible that placing cyberbullying in the context of traditional bullying may hinder our ability to comprehensively define this new concept. Studying cyberbullying by applying existing concepts from another form of bullying may limit the ability to approach cyberbullying with fresh ideas and new constructs. However, separating cyberbullying from the overall context of bullying may limit our understanding of how bullying risks, actions and consequences may vary across the life course. Rather than developing a single definition of bullying, future efforts may wish to consider developing a repertoire of case examples of bullying, or a conceptual model that describes concepts that are critical to bullying across different settings or age ranges.

Participants generally agreed that bullying behaviors among older adolescents could include attacking victims at the level of their beliefs or character. This finding may be concerning as college presents a unique time period where bullying may have harmful effects. Many students are living away from their homes, families, and familiar environments for the first time and are newly independent [18]. While navigating these developmental challenges, older adolescents are also progressing through a stressful, vulnerable period of identity formation [19]. Therefore, attacks during this period may have a significant impact. Further, if left unchecked, these bullies may continue their behavior into adulthood and the workplace. Workplace bullies have been characterized as manipulating others to gain power or privilege, often through subtle techniques that do not involve being directly hostile [20]. These techniques share similarities with participants' descriptions of cyberbullying. Thus, the college years may represent the last opportunity to identify or intervene with bullies, as well as victims, before patterns and consequences are established that may impact the years ahead.

Another finding from our study is that participants' comments suggested that most college students had exposure to a case or had personal experiences with cyberbullying in college. These comments may suggest that cyberbullying is more common that previously thought in college, or they may reflect our study design of focus groups and that many participants wanted to contribute to discussions. Likely it suggests that college students are aware of cyberbullying as an issue on college campuses, and are 
willing and enthusiastic to discuss their views. This suggests that future studies on this topic using qualitative methods such as participant interviews or focus groups may be well received by this population.

This study is not without limitations. Although the sample was largely ethnically homogenous, we included students from a variety of college communities. The demographics of our study participants reflect the demographic makeup of the school involved in the study, which meant that not all ethnic groups were represented. For this reason, future studies should attempt to capture the perspectives of students from a wider range of groups. Second, there may be recruitment bias as people who have had either more or less experience with cyberbullying may have been more or less attracted to participate in the study. Last, we did not elicit personal experiences from participants with the intention of providing students with a comfortable environment to discuss these issues, but it is possible that asking individual students directly about real life examples may have been more informative in characterizing cyberbullying behaviors.

Despite these limitations, our findings have important implications. Without a widely known and accepted definition of cyberbullying, it may be difficult to both identify cases and design interventions to combat this problem. However, future work can use our findings through participant viewpoints and voices in several ways. First, researchers conducting studies of cyberbullying in older adolescents can consider novel approaches to assess these behaviors. Rather than selecting one of many proposed definitions of cyberbullying, future studies could examine the prevalence of cyberbullying by providing specific examples of behaviors to adolescents such as "hacking into another person's Facebook profile”. Providing examples to illustrate types of cyberbullying may lead to accurate prevalence assessments and an understanding of which behaviors are most salient during particular stages of adolescence. Alternatively, researchers may benefit from an interdisciplinary approach to develop a conceptual model that takes into account different bullying actions across life stages. Second, findings suggest a small but vocal group of students who argued that college students were too mature to engage in cyberbullying, and those specific cases suggested as bullying behaviors were "just kind of funny." This group may merit further investigation as to motivations for engaging in behaviors that are considered bullying by others. Third, for clinicians and educators, future work is needed to consider cyberbullying screening across the full span of adolescence. Novel prevention approaches using social media to disseminate interventions or raise awareness of the negative consequences of bullying may help reach college students. Since cyberbullying takes place online, placing prevention or intervention messages in the online space may allow broach reach and dissemination of effective programs.

\section{Acknowledgments}

This study was funded by support from the University of Wisconsin Department of Pediatrics. The authors would like to acknowledge Lyn Turkstra for her assistance with this project.

\section{Author Contributions}

Rajitha Kota developed study proposal, collected data, analyzed data, wrote and edited manuscript. Shari Schoohs collected data, contributed to analysis, contributed to editing manuscript. Meghan Benson advised on study proposal, contributed to analysis, and edited the manuscript. Megan A. Moreno advised on study proposal, contributed to analysis, and edited the manuscript. 


\section{Conflicts of Interest}

The authors declare no conflict of interest.

\section{References and Notes}

1. U.S. Department of Justice. Research and Evaluation on Children Exposed to Violence. Available online: https://ncjrs.gov/pdffiles1/nij/s1001042.pdf (accessed on 27 January 2014).

2. Smith, P.K.; Mahdavi, J.; Carvalho, M.; Fisher, S.; Russell, S.; Tippett, N. Cyberbullying: Its nature and impact in secondary school pupils. J. Child Psychol. Psychiatr. 2008, 49, 376-385.

3. Slonje, R.; Smith, P.K. Cyberbullying: Another main type of bullying? Scand. J. Psychol. 2008, 49, 147-154.

4. Ybarra, M.L.; Mitchell, K.J.; Wolak, J.; Finkelhor, D. Examining Characteristics and Associated Distress Related to Internet Harassment: Findings from the Second Youth Internet Safety Survey. Pediatrics 2006, 118, e1169-e1177.

5. Patchin, J.W.; Hinduja, S. Bullies move beyond the schoolyard a preliminary look at cyberbullying. Youth Violence Juv. Justice 2006, 4, 148-169.

6. Beran, T.; Li, Q. The relationship between cyberbullying and school bullying. J. Stud. Wellbeing 2007, 1, 15-33.

7. Li, Q. A cross-cultural comparison of adolescents' experience related to cyberbullying. Educ. Res. 2008, 50, 223-234.

8. Juvonen, J.; Gross, E.F. Extending the school grounds?-Bullying experiences in cyberspace. J. Sch. Health 2008, 78, 496-505.

9. Center for Disease Control and Prevention. Featured Topic: Bullying Research. Available online: http://www.cdc.gov/violenceprevention/youthviolence/bullyingresearch/index.html (accessed on 20 January 2014).

10. Lenhart, A.; Purcell, K.; Smith, A.; Zickhur, K. Social Media and Young Adults; Pew Internet and American Life Project: Washington, DC, USA, 2010.

11. MacDonald, C.D.; Roberts-Pittman, B. Cyberbullying among college students: Prevalence and demographic differences. Soc. Behav. Sci. 2010, 9, 2003-2009.

12. Molluzzo, J.C.; Lawler, J. A Study of the Perceptions of College Students on Cyberbullying. Inf. Syst. Educ. J. 2012, 10, 84-109.

13. Kosciw, J.; Greytak, E.A.; Bartkiewicz, M.J.; Boesen, M.J.; Palmer, N.A. The 2007 National School Climate Survey: The Experiences of Lesbian, Gay, Bisexual and Transgender Youth in Our Nation's Schools; Gay Lesbian and Straight Education Network (GLSEN): New York, NY, USA, 2008.

14. Krueger, R.A.; Casey, M.A. Focus Groups: A Practical Guide for Applied Research, 4th ed.; SAGE Publications: Thousand Oaks, CA, USA, 2009.

15. Glesne, C. Becoming Qualitative Researchers, 2nd ed.; Addison Wesley Longman: Reading, MA, USA, 1999.

16. Glaser, B.G.; Strauss, A. The Discovery of Grounded Theory: Strategies for Qualitative Research; Aldine Transaction: Hawthorne, New York, NY, USA, 1967. 
17. Varjas, K.; Henrich, C.C.; Meyers, J. Urban middle school students’ perceptions of bullying, cyberbullying, and school safety. J. Sch. Violence 2009, 2, 159-176.

18. Ross, S.E.; Niebling, B.C.; Heckert, T.M. Sources of stress among college students. Coll. Student J. 1999, 3, 312-317.

19. Orlofsky, J.L. Sex-role orientation, identity formation and self-esteem in college men and women. Sex Roles 1977, 3, 561-575.

20. Zapf, D.; Escartín, J.; Einarsen, S.; Hoel, H.; Vartia, M. Empirical Findings on Bullying in the Workplace in Bullying and Emotional Abuse in the Workplace: International Perspectives on Research and Practice; Taylor and Francis: London, UK, 2003.

(C) 2014 by the authors; licensee MDPI, Basel, Switzerland. This article is an open access article distributed under the terms and conditions of the Creative Commons Attribution license (http://creativecommons.org/licenses/by/4.0/). 